\title{
6. O ALIENISTA: DECISÃO, RESPONSABILIDADE MORAL E JUSTIÇA
}

\author{
Guilherme de Oliveira Feldens ${ }^{1}$
}

Resumo: O presente artigo objetiva analisar o texto de Machado de Assis na perspectiva do pensador subjetivo de Kierkeggard, destacando as ideias do autor em relação à interioridade, o momento de decisão e a responsabilização ética, fundamentais para uma análise crítica do Direito.

Palavras-chave: Liberdade. Ética. Responsabilidade.

ABSTRACT: The article aims to analyze the text of Machado de Assis in the perspective of Kierkeggard's subjective thinker, highlighting the author's ideas regarding the interior, the moment of decision and accountability ethics, fundamental to a critical analysis of the law.

Keywords: Freedom. Ethics. Responsibility.

\section{Introdução}

Uma primeira leitura da obra $O$ alienista de Machado de Assis parece direcionar o leitor para o tema da "loucura" ou, então, para a crítica direta da pretensão racionalista de estabelecer com nitidez a linha divisória entre Razão e Loucura. Porém, uma leitura mais atenta faz surgir a perspectiva fundamental do presente texto machadiano. Trata-se, sim, de um texto de caráter ético e político que apresenta questionamento fundamentais sobre aspectos como poder, positivismo, imparcialidade, responsabilidade moral e justiça. Assim, não são os "loucos" os objetos centrais da trama, mas sim o "poder" que produz "loucura", materializado no personagem de Simão Bacamarte.

\footnotetext{
${ }^{1}$ Mestre e Doutorando em Filosofia. Professor do Curso de Direito. Coordenador Adjunto do Curso de Direito - CESUCA.
} 
Dentro desse contexto, o presente artigo objetiva questionar o poder de todo e qualquer saber que pretenda ser rigorosamente objetivo e universal, destacando sua incapacidade para enfrentar graves problemas éticos e políticos. Pretende-se demonstrar que qualquer procedimento de decisão e de justiça, quando equiparada a regras objetivas universais, estará revestido de força e violência. Também pretende analisar a possibilidade de um critério de justiça calcado no "indecidível", capaz de fundamentar uma verdadeira responsabilidade ética daquele que decide. Tais ideias apresentam-se aptas a definir o caráter fundamental da Justiça como uma resposta às experiências concretas, fugindo das abstrações modernas e reconhecendo a possibilidade de compreender que a "verdadeira" justiça não se preocupa tanto com a aplicação abstrata de um procedimento racional, mas busca responder aos casos concretos de sofrimento, dando mais ênfase a uma responsabilidade ética.

\section{Objetividade e Subjetividade em $O$ alienista}

Na primeira parte da obra Post Scriptum conclusivo não científico às migalhas filosóficas, intitulada O problema objetivo da Verdade do Cristianismo, Kierkegaard analisa a "objetividade" como um projetoepistemológico. Situada no interior da polêmica subjetividade/ objetividade; sistema/existência; o filósofo dinamarquês, sob a pena de Johnannes Climacus, desenvolve argumentos capazes de demonstrar que uma doutrina objetiva-especulativa fracassa ao tentar provar a verdade do cristianismo, pois "tão logo a verdade objetiva tenha sido alcançada, a apropriação fica sendo coisa de pouca monta, segue como um brinde, e em última análise, tudo o que tem a ver com o indivíduo é indiferente" (Kierkegaard, 1992).

Nesse contexto, Kierkegaard salienta que sua época se tornou tão objetiva, que "até a esposa de um funcionário público argumenta a partir da totalidade, do Estado, da ideia de comunidade, da cientificidade geográfica, para chegar ao indivíduo" (Kierkegaard, 1992). Desse modo, todos os elementos éticos são tratados como um fenômeno histórico. O pensador objetivo tem o conceito como sua única referência, 
coloca-se como um observador externo, a ponto de não falar de si mesmo ${ }^{2}$. Para Simão Bacamarte a verdade é algo exterior; é indiferente aceitá-la ou não, pois se trata apenas de penetrá-la com pensamento especulativo (Kierkegaard, 1992, p. 26).

Na objetividade, o especulante não levanta o problema de sua existência, pois, "enquanto especulante, ele se torna precisamente objetivo demais para se preocupar com sua própria felicidade eterna" (Kierkegaard, 1992). Para Simão Bacamarte, uma responsabilidade ética não é de modo algum relevante, já que sua tarefa consiste em afastar-se de si mesmo ${ }^{3}$. Não há uma opinião verdadeiramente própria, pois o objetivo final é o saber absoluto. Nessa objetividade do conceito, a interioridade fica absorvida pela verdade universal, pelo exterior.

Na Ciência da lógica, Hegel apresenta sua tese da relação, em que fundamenta a identidade do exterior e do interior, do racional e do real: "o exterior é por isso mesmo, em primeiro lugar, o mesmo conteúdo do interior. Aquilo que é interior existe também exteriormente, e vice-versa; o fenômeno não mostra nada que não seja na essência, e na essência não tem nada que não seja manifestado" (Hegel, 1968, p. 454). Porém, conforme afirma Climacus (Kierkegaard, 1992, p. 111), "nenhum padre confessor que tenha escutado um segredo para guardar, nenhuma jovem que tenha prometido a si mesma e à sua paixão amorosa o silêncio" concordaria com a total indiferença entre o interior e o exterior. Se o axioma hegeliano fosse verdadeiro, a distinção entre a igreja

\footnotetext{
${ }^{2}$ Tal característica fica evidente na seguinte passagem do texto de Machado de Assis: "Uma vez desonerado da administração, o alienista procedeu a uma vasta classificação dos seus enfermos. Dividiu-os primeiramente em duas classes principais: os furiosos e os mansos; daí passou às subclasses, monomanias, delírios, alucinações diversas. Isto feito, começou um estudo aturado e contínuo; analisava os hábitos de cada louco, as horas de acesso, as aversões, as simpatias, as palavras, os gestos, as tendências; inquiria da vida dos enfermos, profissão, costumes, circunstâncias da revelação mórbida, acidentes da infância e da mocidade, doenças de outra espécie, antecedentes na família, uma devassa, enfim, como a não faria o mais atilado corregedor. E cada dia notava uma observação nova, uma descoberta interessante, um fenômeno extraordinário. Ao mesmo tempo estudava o melhor regímen, as substâncias medicamentosas, os meios curativos e os meios paliativos, não só os que vinham nos seus amados árabes, como os que ele mesmo descobria, à força de sagacidade e paciência. Ora, todo esse trabalho levava-lhe o melhor e o mais do tempo. Mal dormia e mal comia; e, ainda comendo, era como se trabalhasse, porque ora interrogava um texto antigo, ora ruminava uma questão, e ia muitas vezes de um cabo a outro do jantar sem dizer uma só palavra a D. Evarista". (Machado de Assis, 1998, p.5 ).

${ }^{3} \mathrm{O}$ afastar-se de si mesmo fica muitas vezes bem definido em $\mathrm{O}$ alienista, como se percebe na seguinte passagem: "Conquanto as lágrimas de D. Evarista fossem abundantes e sinceras, não chegaram a abalá-lo. Homem de ciência, e só de ciência, nada o consternava fora da ciência; e se alguma coisa o preocupava naquela ocasião, se ele deixava correr pela multidão um olhar inquieto e policial, não era outra coisa mais do que a idéia de que algum demente podia achar-se ali misturado com a gente de juízo" (Machado de Assis, 1998, p. 7).
} 
visível e a invisível deveria ser abolida. Tudo deveria ser tratado como um fenômeno histórico a ser observado objetivamente. A existência estaria assentada na generalidade do mundo histórico, absorvida na coletividade, inserida no processo de desenvolvimento do Espírito.

Segundo Kierkegaard, no modelo hegeliano não há a necessária distinção entre a história geral e a história individual, não há separação entre a existência tomada pela exterioridade e a interioridade ${ }^{4}$. Um pensador objetivo, como em $O$ alienista, não assume nenhum compromisso com o seu existir, "ele pergunta, assim, pela verdade, mas não pela verdade subjetiva, a verdade da apropriação" (Kierkegaard, 1992). Ele leva uma postura não interessada pessoalmente de modo infinito. Sua existência não condiz com a realidade, está presa a um sistema formal e objetivo ${ }^{5}$.

Kierkegaard, em contraposição a figura de Simão Bacamarte, defende a busca por compreensão da sua própria realidade existencial. Assim, ele apresenta a figura do pensador subjetivo como aquele que pensa sua existência, que coloca sua vida e sua reflexão em um mesmo processo, buscando compreender sua própria realidade. Ele critica Hegel afirmando o primado da subjetividade enquanto interioridade em relação à objetividade, defendendo a existência como um paradoxo, sem nenhuma sistematização. A superação de contradições só é possível no interior da lógica, através do pensamento, não podendo ser aplicada ao plano da existência.

Kierkegaard também demonstra que a especulaçãodo alienistanãopodeser o modosupremo da ética, já que, como um atode apropriação, a moralpertence ainterioridade. Na objetividade sistêmica,o indivíduoabandona o discursona primeira pessoa eprocura pelaimpessoalidade e pelo desinteresse. De forma sistemática

\footnotetext{
${ }^{4} \mathrm{Em}$ oposição a esse posicionamento podemos citar a seguinte analogia apresentada por Kierkegaard:"Tomemos um casal de esposos. Vejam, o casamento deles, claramente, deixa sua marca no mundo exterior; ele constitui um fenômeno na existência (em escala menor, tal como o cristianismo, pensado em sua faceta histórico-mundial, deixou sua marca na vida toda); mas o seu amor conjugal não é um fenômeno histórico; o fenomênico é o insignificante, tem significado para os cônjuges apenas através do amor de cada um, mas observado de alguma outra maneira (isto é, objetivamente), o fenomênico é uma ilusão. Assim é também com o cristianismo. Isso é assim tão original?"(Kierkegaard, 1992, p. 38).

${ }^{5}$ Conforme professa Simão Bacamarte, "Suponho o espírito humano uma vasta concha, o meu fim, Sr. Soares, é ver se posso extrair a pérola, que é a razão; por outros termos, demarquemos definitivamente os limites da razão e da loucura. A razão é o perfeito equilíbrio de todas as faculdades; fora daí insânia, insânia e só insânia" (Machado de Assis, 1998, p. 10)
} 
eintencional, ele seafasta detodas as questões existenciais e, consequentemente, se afasta da individualização ${ }^{6}$.

A verdade é, portanto, subjetiva; só existe para o indivíduo. Ela está relaciona a existência do individuo, fazendo com que só tenha sentido ao ser apropriada por ele. A verdade torna o ser humano livre, e de maneira ilimitada ${ }^{7}$. Suas ideias apresentam-se, então, incompatíveis com o determinismo lógico Hegeliano, pois qualquer forma de absoluto que não seja a liberdade contraria a liberdade. Kierkegaard insiste contra a existência de um determinismo; insiste na responsabilização individual.

Clímacusassume a posiçãodequea busca porconhecimento objetivo não rendemais do que umaaproximação: "História efilosofia especulativasão similares no sentido de que uma históriafinal destaou daquela nãopode ser escrita, de forma que nenhumsistema finalfilosóficopode ser escrito" (Westphal, 1999). O conhecimento é, então,um ideal regulador, "e o que conta como conhecimentoem um dado momentoé apenas a última aproximação" (Westphal, 1999).Isto é especialmenteproblemático paraum sistemacomoHegel,paraquem a verdadenão é encontradonas partes, mas apenas no todo.QuandoClímacoconstantemente faz provocações a Hegele seus seguidorescom a sugestão deque o sistemanão está terminado,a incompletudea qualele apontasignifica, em termos hegelianos, a ausência da verdade ${ }^{8}$.

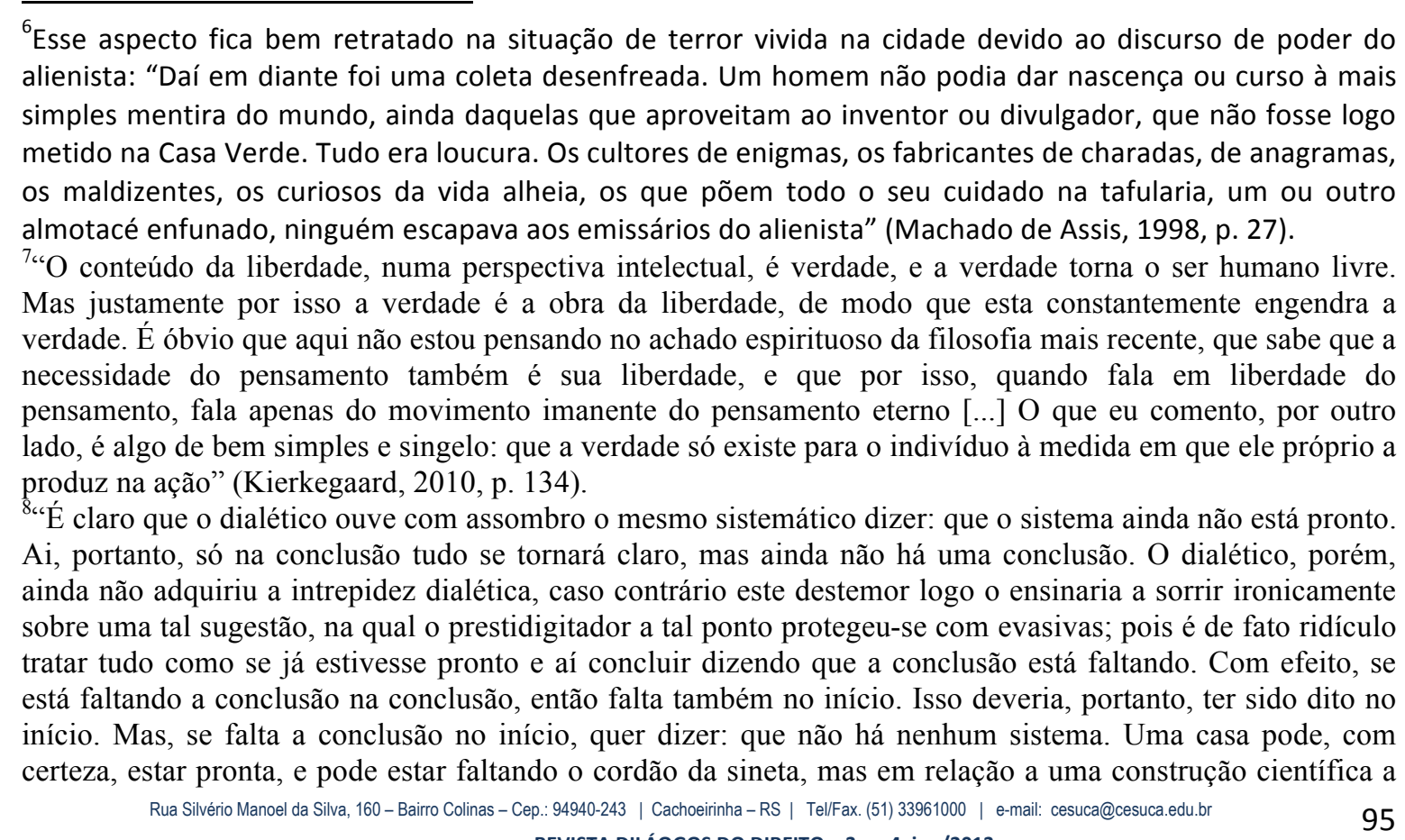
REVISTA DILÁOGOS DO DIREITO v.3, n. 4, jun/2013 
Kierkegaard retira a verdade do isolamento da vida e a insere no existir. Ao contrário do alienista que aborda a verdade na relação sujeito e objeto, o autor dinamarquês coloca a verdade como expressão da singularidade, como algo a ser apropriado pela existência. Enquanto que no personagem machadiano, a objetividade do Estado é a instância suprema da ética ${ }^{9}$, para Kierkegaard a síntese entre o indivíduo singular e o estado acarreta na impessoalidade. Contra toda tentativa de racionalização da interioridade, ele defende a responsabilização pela construção existencial, na contínua apropriação subjetiva da verdade. Assim, toda apropriação e, consequentemente, toda decisão baseia-se na subjetividade.

\section{Conforme expõe o filósofo dinamarquês}

O cristianismo é espírito; espírito é interioridade; interioridade é subjetividade; subjetividade é essencialmente paixão, e, em seu máximo, uma paixão infinita e pessoalmente interessada na felicidade eterna. Logo que se exclui a subjetividade, e se tira da subjetividade a paixão, e da paixão o interesse infinito, não resta absolutamente nenhuma decisão, nem sobre este problema nem sobre qualquer outro. Toda decisão, toda decisão essencial, baseia-se na subjetividade. Um examinador (e é isso a subjetividade objetiva) em nenhum ponto tem uma urgência infinita por uma decisão, e em nenhum ponto ele a vê. Isso é o falsum [a falsidade] da objetividade e o significado da mediação como uma passagem no processo contínuo, no qual nada subsiste e no qual também nada é decidido, porque o movimento retorna sobre si mesmo e de novo retorna, e o próprio movimento é uma quimera, e a especulação é sempre sábia depois que as coisas aconteceram. Objetivamente compreendido, há resultados mais do que suficientes em toda parte, mas nenhum resultado decisivo em parte alguma, o está completamente certo, precisamente porque a decisão se baseia na subjetividade, essencialmente na paixão, e, maxime [em seu máximo], na paixão pessoal e infinitamente interessada pela felicidade eterna. (Kierkegaard, 1992, p. 26)

falta de uma conclusão tem o poder retroativo de tornar o início duvidoso e hipotético, ou seja, nãosistemático. Assim seria com a intrepidez dialética. Mas o dialético ainda não a adquiriu. Consequentemente, com recato juvenil, ele se abstém de qualquer conclusão no que se refere à ausência de uma conclusão - e, cheio de esperança, começa seu trabalho" (Kierkegaard, 1992, p. 48).

${ }^{9}$ A objetividade ética suprema do Estado é apresentada no momento em que Simão Bacamarte declara que não dá razão dos seus atos de alienista "a ninguém, salvo aos mestres e a Deus. Se quereis emendar a administração da Casa Verde, estou pronto a ouvir-vos; mas, se exigis que me negue a mim mesmo, não ganhareis nada. Poderia convidar alguns de vós em comissão dos outros a vir ver comigo os loucos reclusos; mas não o faço, porque seria dar-vos razão do meu sistema, o que não farei a leigos nem a rebeldes". (Machado de Assis, 1998, p. 20). 
Ele contrapõe-se a todo discurso racionalista apontando suas ideias para o homem sozinho, esse homem que somos todos e cada um de nós em particular; no qual há sempre um ato de vontade, uma decisão colocada pelo indivíduo. Cada indivíduo deve ser então o "autor de sua existência". Para o filósofo dinamarquês, não há uma lógica absoluta regendo a história e a existência do indivíduo,mas há sim um caráter essencial da subjetividade, que não encontra nenhum regramento prévio $^{10}$.

Portanto, pode haver um sistema lógico; mas não pode haver um sistema da existência. Em um sistema lógico não se pode acolher nada que tenha uma relação com a existência. "A existência mesma é um sistema - para Deus, mas não pode sê-lo para algum espírito existente. Sistema e completude se correspondem mutuamente, mas existência é justamente o contrário" (Kierkegaard, 1992). Visto abstratamente, sistema e existência não podem ser pensados conjuntamente, porque, para pensar a existência, o pensamento sistemático precisa pensá-la como superada e, portanto, não como existente. "Existência é o que abre espaço, que aparta um do outro; o sistemático é a completude, que reúne" (Kierkegaard, 1992).

Kierkegaard nos faz refletir sobre a necessidade de abordar o homem em um sentido cada vez mais autêntico. Destaca a importância de constituição própria da subjetividade nos indivíduos como uma opção a uma realidade de massificação de comportamento e de escolhas, que faz com que os indivíduos não assumam as suas próprias certezas e os seus próprios planos de vida. Seu pensamento contrapõe-se ao homem preso por modelos externos impositivos, pois as verdadeiras escolhas são aquelas que nascem no interior de cada um, de maneira autêntica. Os projetos especulativos de

\footnotetext{
${ }^{10} \mathrm{Na}$ obra $O$ conceito de angústia, Kierkegaard apresenta a ideia de que diante da vida há várias opções possíveis; um terreno infinito de possibilidades e, portanto, de angústia. Dessa forma, é necessário mergulhar fundo na angústia, na infinitude das possibilidades, para que se escolha o melhor caminho. É angustiando-se e escolhendo que o indivíduo se forma e constrói a si mesmo; "decidir é arriscar-se" e isto gera angústia. Assim sendo, o sentimento de angústia tem grande importância na construção da subjetividade do indivíduo e na sua auto-afirmação, fazendo com que ele exerça a sua liberdade de escolha em total consonância consigo próprio e com a sua verdade. Segundo o autor $(2010$, p. 55), "a angústia é a vertigem da liberdade, que surge quando o espírito quer estabelecer a síntese, e a liberdade olha para baixo, para sua própria possibilidade, e então agarra a finitude para nela firmar-se (...), mas ao mesmo tempo a angústia é a coisa mais egoísta que há, e nenhuma expressão concreta da liberdade é tão egoísta como a possibilidade de qualquer concreção. Isto é, uma vez mais, o elemento que oprime, que determina a relação ambígua do indivíduo, de simpatia e antipatia. Na angústia reside a infinitude egoísta da possibilidade, que não tenta como uma escolha, mas angustia, insinuante, com sua doce ansiedade."
} 
sua época deixaram a maioria dos indivíduos imersos em uma existência alheia a seus próprios projetos de vida, em uma realidade que ao invés de lhes oferecer uma suposta segurança, os faz se perder cada vez mais. Este quadro de falsa segurança resulta no sacrifício da individualidade, fazendo com que os sujeitos vivam sem autenticidade.

\section{Segundo o autor}

Na herança que passa de geração em geração, levou-se adiante a ilusão de que o método é o correto, mas que os eruditos investigadores ainda não tiveram sucesso, etc. Todos parecem sentir-se bem; e se tornam sempre mais objetivos. A atitude de interesse pessoal, infinito e apaixonado do sujeito (que constitui a possibilidade da fé e, consequentemente, a fé; é a forma da felicidade eterna e, consequentemente, a felicidade eterna) desvanece-se mais e mais porque a decisão é adiada, e o adiamento é um resultado direto dos resultados do erudito investigador. Isto quer dizer: o problema simplesmente nem surgiu; a gente se tornou objetiva demais para ter uma felicidade eterna, porque esta felicidade é inseparável, precisamente, da atitude de interesse infinito, pessoal e apaixonado, e é precisamente a isso que se renuncia para se tornar objetivo; é precisamente isso que é surrupiado da gente pela objetividade (Kierkegaard, 1992, p. 41)

Neste aspecto, as ideias de Kierkegaard podem ser lidas como a necessidade de "assumir-se a si mesmo", como uma opção absoluta e irreversível do indivíduo rumo à liberdade verdadeira. Torna-se fundamental, portanto, constatar que a retirada do indivíduo do processo de criação de sua própria verdade, de seu próprio projeto existencial o atira a uma sociedade alienada, regida por princípios sistemáticos de comportamento, dando origem a um vazio existencial, já que esta realidade não é suficiente para dar sentido a uma vida ${ }^{11}$. A sua existência, ao contrário, deve ser a sua própria vontade, compatível com as exigências mais profundas do seu interior ${ }^{12}$.

Assim, para que a individualidade não se perca na generalidade o indivíduo deve se livrar de todo conformismo e descobrir a possibilidade de existir autenticamente, de fazer-se a si mesmo, o que é fundamental, pois a falta de uma definição autêntica faz com

\footnotetext{
${ }^{11}$ Segundo Kierkegaard (1992, p. 50), "aquilo de que o mundo talvez tenha sempre carecido é o que se poderia chamar de individualidades autênticas, subjetividades decididas, aquelas artisticamente permeadas de reflexão, as que pensam por si mesmas, as quais são diferentes das que só berram e das que só ensinam”.

12،"Enquanto o pensamento objetivo investe tudo no resultado e leva toda a humanidade a trapacear, copiando e repetindo de cor o resultado e a resposta, o pensamento subjetivo investe tudo no devir e omite o resultado, em parte porque este justamente pertence a ele, já que ele possui o caminho, e em parte porque ele, como existente, está continuamente no devir, como todo ser humano que não se deixou enganar para tornar-se objetivo, para converter-se, de modo não-humano, em especulação" (Kierkegaard, 1992, p. 16)
} 
que o homem não conheça seu sentido e se perca na generalidade, sentindo o vazio existencial em que está suspenso.

Conforme salienta Climacus, "para o estudo do ético, todo ser humano é reportado a si mesmo. Ele próprio é, nessa questão, mais do que suficiente para si mesmo; sim, ele é o único lugar onde ele pode, com segurança, estudar esse assunto" (Kierkegaard, 1992). Por meio de seus projetos existenciais, o existente se deixa envolver nas teias da vida, ficando cada vez mais difícil separar o ético do exterior, e tão mais facilmente o axioma metafísico hegeliano, de que o exterior é o interior, e o interior, o exterior, parece ser reforçado. Porém, esta é, precisamente, a tentação, e por isso "o ético se torna a cada dia mais difícil, na medida em que ele se situa na verdadeira exaltação da infinitude, que constitui o começo, onde ele se manifesta, por isso, mais claramente" (Kierkegaard, 1992).

A obra $O$ alienista destaca a importância do indivíduo e das suas escolhas lógicas ou ilógicas; a importância de sua liberdade para escolher, o que significa ter uma completa responsabilização individual pela sua própria realização, pela falta de um "sistema" inteligível acabado para a existência do homem, que significaria já uma limitação à sua liberdade.É necessário mergulhar fundo na infinitude das possibilidades para escolher o melhor caminho, pois esse sentimento faz com que os indivíduos exerçam a sua liberdade de escolha em total consonância consigo próprio e com a sua verdade ${ }^{13}$..

\section{Justiça e Subjetividade}

As ideias acima expostas, conjugadas com o texto de Machado de Assis, levantam um segundo aspecto crítico relacionado com a necessária separação entre justiça e preceitos legais/racionais. Como aponta Derrida, a justiça não pode ser obtida por meio de regras, ela não está sujeita a cálculos, mas sim a experiência do impossível, é o singular, o incalculável ${ }^{14}$; e nunca a generalidade de uma regra, de um imperativo

\footnotetext{
${ }^{13}$ Kierkegaard, Soren. Emmanuel. The concepto of anxiety.Princeton: University Press, 1980.p. 134.

${ }^{14}$ Segundo Derrida (2007, p. 30), "a justiça seria, deste ponto de vista, a experiência daquilo que não podemos experimentar. Mas acredito que não há justiça sem essa experiência da aporia, por impossível que seja. A justiça é uma experiência do impossível. Uma vontade, um desejo, uma exigência de justiça cuja estrutura, não fosse uma experiência da aporia, não teria nenhuma chance de ser o que ela é, a saber, apenas um apelo à justiça. $O$ Direito não é justiça. $O$ direito é o elemento do cálculo, é justo que haja um direito, mas a justiça é incalculável, ela exige que se calcule o incalculável; e as experiências aporéticas são experiências tão improváveis quanto necessárias da justiça, isto é, momentos em que a decisão entre o justo e o injusto nunca é garantida por uma regra."
} 
universal $^{15}$. Assim sendo, a aplicação de um mesmo critério de justiça para todos acaba por excluir esse caráter de apreciação das singularidades, ficando elas absorvidas pelo todo. Consequentemente, a condição especial de determinados cidadãos fica colocada em segundo plano. Todos passam a ser "moradores" da "Casa Verde". O terror acentuase e "já não se sabe quem estava são, nem quemestava doido" (Machado de Assis, 1998, p. 16).

Uma concepção de justiça como experiência do "indecidível"colocaa aplicação objetiva de um procedimento previamente estipulado em uma condição muito difícil ${ }^{16}$. A fundação e a instauração de um projeto racionalista nos moldes de Simão Bacamarte só pode apoiar-se sobre ela mesma, sendo uma violência sem fundamento. A justiça dentro de uma ordem de cálculo serve apenas como legitimador de injustiças. Derrida, ao colocar a justiça como infinita, incalculável, rebelde as regras, impõe que o momento da decisão precisa ser um momento de urgência e de precipitação (de "loucura"), não tendo o efeito de um saber teórico ${ }^{17}$. A decisão justa deve rasgar o tempo e desafiar as dialéticas. Ela deve trazer em seu bojo a ação livre e responsável como condição do exercício da justiça. Sem liberdade uma decisão não pode ser considerada justa ou injusta $^{18}$. Para que uma decisão possa ser tida como justa (livre e responsável) é preciso que ela seja diferente e criativa, exigindo-se uma interpretação únicaque nenhuma regra existente pode garantir. A justiça não espera, não permite a busca infinita por conteúdos e formas que possam justificá-la.

Deve-se insistir contra a existência de um determinismo; insistir na responsabilização individual. Há uma fundamental necessidade de ser livre para poder optar; sem saber se aquilo que se opta é melhor ou pior.Somente quando o indivíduo se livra deste conformismo descobre a real possibilidade proposta por Derrida de uma justiça na condição de "por vir"19 ${ }^{19}$ Só assim será possível impor uma responsabilidade sem limite diante das decisões ético-políticas, servindo como uma manifestação da

\footnotetext{
${ }^{15}$ Derrida, Jacques. Força de lei: O Fundamento místico da autoridade. São Paulo: Martins Fontes, 2007. p. 31.

${ }^{16}$ Ibid., p. 192.

${ }^{17}$ Ibid., p. 195.

${ }^{18}$ Derrida, Jacques. Força de lei: O Fundamento místico da autoridade. São Paulo: Martins Fontes, 2007. p. 50 .

${ }^{19}$ DERRIDA, Jacques. Força de lei: O Fundamento místico da autoridade. São Paulo: Martins Fontes, 2007.
} p. 193. 
potencialidade criadora do ser humano, capaz de intervir de modo eficiente nos problemas da sociedade atual.

\section{Conclusão}

A análise desenvolvida nesse artigo demonstra que a obra de Machado de Assis possui um forte apelo crítico, capaz de oferecer uma tentativa de superação da tradição do pensamento procedimentalista, característico na modernidade, que permanece prisioneiro do autismo originário das teorias racionalistas, responsáveis pela universalização de conceitos e de negação das singularidades. Dentro deste contexto, a restauração de qualquer injustiça torna-se efeito secundário da preservação da ordem e da segurança do procedimento, que fornece um padrão objetivo de justiça. Estas teorias acabam por conceber um sistema jurídico insuficiente, pois separam a justiça da responsabilização moral das decisões humanas.

As ideias apresentadas pelo escritor são aptas a definir o caráter fundamental da Justiça como uma resposta às experiências concretas, fugindo das abstrações modernas e reconhecendo a possibilidade de compreender que a "verdadeira" justiça não se preocupa tanto com a aplicação abstrata do procedimento legal, mas busca responder aos casos concretos de sofrimento. Esse tipo de justiça visa, primeiramente, responder a uma nova moral, capaz de dar resposta às experiências de injustiça, fugindo da universalização desse conceito feito na modernidade e tentando aproximar-se ao indivíduo em sua singularidade. Esta perspectiva é de extrema importância, pois permite uma singular visão da realidade, imprescindível para um compromisso ético dos cidadãos.

\section{REFERÊNCIAS BIBLIGRÁFICAS}

DERRIDA, Jacques. Força de lei: O Fundamento místico da autoridade. São Paulo: Martins Fontes, 2007.

HEGEL, Georg Wilhelm. Friedrich. Filosofia da História. Brasília: Unb, 1995.

. Ciencia de la lógica. Buenos Aires: Solar, 1968. 754 p.

KIERKEgAARD, S. A. Concluding Unscientific Postscript to Philosophical Fragments. New Jersey: PrincetonUniversity Press, 1992. 

ISSN 2316-2112

O conceito de angústia. Petrópolis: Vozes, 2010.

.Pós-Escrito conclusivo não-científico às migalhas filosóficas. Tradução em andamento Álvaro Valls.

MACHADO DE ASSIS, Joaquim Maria. O Alienista. São Paulo: Ática, 1998.

WESTPHAL, Merold. Kierkegaard and Hegel. In: MARINO, Gordon (Org.). The

CambridgeCompanion to Kierkegaard. Cambridge, Mass.: Cambridge University Press, 1999. 